\title{
Maternal post-traumatic stress and depression symptoms and outcomes after NICU discharge in a low-income sample: a cross-sectional study
}

Kameelah Gateau ${ }^{1,2}$, Ashley Song 2,3, Douglas L. Vanderbilt ${ }^{4}$, Cynthia Gong ${ }^{2,5}$, Philippe Friedlich², Michele Kipke ${ }^{6}$ and Ashwini Lakshmanan ${ }^{2,5,7^{*}}$ (D)

\begin{abstract}
Background: Having a preterm newborn and the experience of staying in the neonatal intensive care unit (NICU) has the potential to impact a mother's mental health and overall quality of life. However, currently there are few studies that have examined the association of acute post-traumatic stress (PTS) and depression symptoms and infant and maternal outcomes in low-income populations.

Design/ methods: In a cross-sectional study, we examined adjusted associations between positive screens for PTS and depression using the Perinatal Post-traumatic stress Questionnaire (PPQ) and the Patient Health-Questionnaire 2 (PHQ-2) with outcomes using unconditional logistic and linear regression models.

Results: One hundred sixty-nine parents answered the questionnaire with 150 complete responses. The majority of our sample was Hispanic (68\%), non-English speaking (67\%) and reported an annual income of $<\$ 20,000$ (58\%). 33\% of the participants had a positive PPQ screen and 34\% a positive PHQ-2 screen. After adjusting for confounders, we identified that a positive PHQ-2 depression score was associated with a negative unit $(95 \% \mathrm{Cl})$ change on the infant's Vineland Adaptive Behavior Scales, second edition of $-9.08(-15.6,-2.6)(p<0.01)$. There were no significant associations between maternal stress and depression scores and infant Bayley Scales of Infant Development III scores or re-hospitalizations or emergency room visits. However, positive PPQ and screening score were associated with a negative unit $(95 \% \mathrm{Cl})$ unit change on the maternal Multicultural Quality of Life Index score of $-8.1(-12,-3.9)(p<0.01)$ and $-7.7(-12,-3)(p=0.01)$ respectively.

Conclusions: More than one-third of the mothers in this sample screened positively for PTS and depression symptoms. Screening scores positive for stress and depression symptoms were associated with a negative change in some infant development scores and maternal quality of life scores. Thoughtful screening programs for maternal stress and depression symptoms should be instituted.
\end{abstract}

Keywords: Post-traumatic stress, Post partum depression, Low-income, NICU

\footnotetext{
* Correspondence: alakshmanan@chla.usc.edu

${ }^{2}$ Fetal and Neonatal Medicine Institute, Division of Neonatal Medicine, Children's Hospital Los Angeles, Keck School of Medicine, University of Southern California, 4650 Sunset Boulevard, MS \#31, Los Angeles, CA 90027, USA

${ }^{5}$ Leonard D. Schaeffer Center for Health Policy and Economics, University of Southern California, Los Angeles, CA, USA

Full list of author information is available at the end of the article
}

C The Author(s). 2021 Open Access This article is licensed under a Creative Commons Attribution 4.0 International License, which permits use, sharing, adaptation, distribution and reproduction in any medium or format, as long as you give appropriate credit to the original author(s) and the source, provide a link to the Creative Commons licence, and indicate if changes were made. The images or other third party material in this article are included in the article's Creative Commons licence, unless indicated otherwise in a credit line to the material. If material is not included in the article's Creative Commons licence and your intended use is not permitted by statutory regulation or exceeds the permitted use, you will need to obtain permission directly from the copyright holder. To view a copy of this licence, visit http://creativecommons.org/licenses/by/4.0/ The Creative Commons Public Domain Dedication waiver (http://creativecommons.org/publicdomain/zero/1.0/) applies to the data made available in this article, unless otherwise stated in a credit line to the data. 


\section{Background}

Preterm birth is a significant contributor to neonatal and under five morbidity and mortality worldwide [1]. Of those who survive beyond the neonatal period, many very low birth weight (VLBW infants < $1500 \mathrm{~g}$ ) [2] face significant lifelong disabilities including neurocognitive deficits and visual impairment, along with systemic illnesses including respiratory and cardiac disabilities while late preterm infants also have been shown to have poorer neurodevelopmental outcomes and worse Total School Readiness Scores at kindergarten [3, 4]. In addition to the morbidities preterm infants potentially face, there is also significant economic, psychosocial and emotional impact on the families [5].

Many studies have evaluated the various emotional and mental health challenges that the mothers of neonates, both term and preterm, that can present at birth and in the first few years after NICU discharge [6, 7]. One systematic review by Gavin et al. reviewed current available literature on the incidence and prevalence of perinatal depression, and found that in the time period during pregnancy to 3 months post-delivery, up to $19 \%$ of women have depressive symptoms with $7.1 \%$ of mothers having major depressive episodes [8]. Of the studies that have assessed mental health outcomes in mothers of preterm neonates, most studies describe mental health perturbations like post-traumatic stress disorder (PTSD) and depression as being strongly associated with the birth of preterm infants [8-15]. Prevalence rates for depression among mothers caring for preterm infants discharged from the NICU have been described to range between 28 and 40\% [16]. Additionally, it has previously been established that when mothers develop mental health problems there is significant impact on parent-child attachment, cognitive, developmental and overall health outcomes in infants $[17,18]$. Given that preterm neonates are a particularly vulnerable population already with an increased risk of poor health outcomes, it becomes of the utmost importance to identify the factors that contribute to the development of poor mental health outcomes amongst their mothers.

While many studies have evaluated some of the risk factors associated with developing poor mental health outcomes in mothers after their children have been discharged from the NICU, most of these studies have been in homogenous populations, and have not assessed parental maternal health in the discharge period, or have assessed only a few predictors of stress. Furthermore there are still very few studies that have been done amongst socioeconomically diverse populations that have also looked specifically at socio-demographic and medical outcomes of preterm infants post NICU discharge and how those factors potentially impact a mother's overall well-being and mental health. In this study, our objectives were to 1) describe the prevalence of positive screens for acute posttraumatic stress and depression symptoms among low-income families after NICU discharge, 2) examine the adjusted association of PTS and depression symptoms and child neurodevelopmental and medical outcomes and 3) evaluate the adjusted association of PTS and depression symptoms and maternal quality of life.

\section{Methods \\ Study design and participants}

The study design was a single-center, cross-sectional study. One caregiver of preterm (<37 weeks' gestation) infants up to 24 months corrected age with completed developmental assessments attending a high-risk infant follow-up clinic at a quaternary urban children's hospital between 2013 and 2015 was enrolled. A 150-item questionnaire with components validated in English and Spanish was administered to participants about life after discharge from the NICU.. Patient recruitment, survey administration and population characteristics are detailed in previous work $[19,20]$. The Institutional Review Board at Children's Hospital Los Angeles approved the study protocol. Written informed consent was obtained from all study participants.

\section{Measurements}

A summary of the primary outcomes and mental health assessments along with developmental and adaptive assessments are listed below.

\section{Mental health}

PTS and depression symptoms were assessed utilizing the modified Perinatal Posttraumatic Stress Disorder Questionnaire (PPQ) and the Patient Health Questionnaire 2 (PHQ-2). The original PPQ was designed to identify mothers who were experiencing symptoms of post-traumatic stress [21]. Through a series of 14 questions, mothers are asked using a 5-point scale ( 0 being not at all and 4 being often) to assess how frequently they experienced symptoms of post-traumatic stress including flashbacks, fear, avoidance, and hyper vigilance. The standard PPQ assesses these symptoms in individuals by administering it to participants who gave birth up to 4 months before the questionnaire was administered, and for that reason the modified PPQ was developed, which changed the phrasing to present tense to assess symptoms within the immediate postpartum period. The modified PPQ was utilized in our study [22]. Additionally, a PPQ screen was considered positive when a participant acknowledged the presence of six or more symptoms [7]. The PHQ-2 consists of 2 questions that assess the frequency of depression and anhedonia over the previous 2 weeks, with a score ranging from 0 to 6 
[23]. The authors identify a cut-off score of 3 as a clinically meaningful value to screen for depression/anxiety [24]. These tools have been used in similar populations [21, 23].

\section{Medical outcome assessment}

We asked parents questions about their infant's health status since discharge including the number of emergency department visits, monthly clinic appointments and hospitalizations, immunizations, dependence on durable medical equipment, and administration of prescription medications.

\section{Neuro-developmental assessments}

Early development was assessed using the Bayley Scales of Infant and Toddler Development, Third Edition (Bayley-III). The Bayley Scales identify children with developmental delay and assist with planning of appropriate interventions in children aged 1-42 months. The five distinct scales of assessment include Cognitive (91 items), Language (97 items), Motor (138 items), caregiver ratings of Social Emotional (35 items), and Adaptive Behavior (241 items). Cognition is subdivided into two categories: expressive language (48 items) and receptive language (49 items), and motor is assessed as both fine (66 items) and gross (72 items) tasks. The agecorrected mean score of the Bayley-III is 100 with a standard deviation of 15 . A higher score indicates more advanced development [25].

\section{Vineland adaptive behavior scale II (VABS II)}

Personal, social and communication skills were assessed using the Vineland Adaptive Behavior Scales, second edition (VABS-II) [26]. Adaptive behavior refers to an individual's day-to-day activities needed for personal and social sustenance; these scales assess what a person does as opposed to what he or she should be able to do. There are four domains assessed: communication, daily living skills, socialization and motor skills. A composite score is provided across the four domains to summarize an individual's performance. The age-corrected mean is 100 with a standard deviation of 15 with higher scores indicating higher function.

\section{Maternal quality of life}

The multicultural quality of life index (MQLI) from Mezzich et al. was used to assess parent's health status [27]. The MQLI was developed to assess health-related quality of life through targeted areas including: physical well-being, psychological/emotional well-being, self-care, occupational functioning, interpersonal functioning, social-emotional functioning, social emotional support, community and services support, personal and spiritual fulfillment. Participants were asked to rate these domains on a 10 point scale, with 1 being poor and 10 being excellent. They were also asked to self-report their overall health status through a series of 12 yes/no questions and a 5-point overall health rating scale ranging from poor to excellent. Questions asked included those assessing overall health status, limitation on physical activity, energy levels, depression, and pain.

\section{Statistical analysis}

The characteristics of the study population were described using means and proportions. The frequency of covariates (race/ethnicity, income level, maternal education, language, infant birth weight, infant gestational age, neonatal co-morbidities, use of medical equipment and post discharge diagnoses) were compared across PPQ and PHQ-2 scores. $P$-values were derived using t-tests for two group comparisons. Given the small subset of fathers, fathers' responses were excluded from the multivariable analysis. Multivariable logistic regression estimated the adjusted odds of readmissions and emergency room visits and multivariable linear regression estimated adjusted developmental and parental quality of life scores with PPQ and PHQ-2 scores. The models were adjusted for confounders such as race/ethnicity, maternal education, primary language, neonatal comorbidities, post discharge diagnoses and use of medical equipment. Beta coefficients (linear regression results) and odds ratios (ORs) with 95\% confidence intervals (CIs) and two-sided $P$-values for individual variable categories are reported.

We also conducted an E-value analysis for the quality of life outcomes, which is a type of sensitivity analysis that quantifies unmeasured confounding to determine whether unmeasured confounding may have contributed to the observed effects [28]. As detailed in previous work conducted by our group [29], the E-value analysis addresses the extent to which unmeasured confounding may negate the observed results. A relatively low E-value in the context of statistical adjustments made suggests that the results could easily be nullified by a confounder. Conversely, a very high E-value relative to the point estimate may imply that the observed effect is in fact plausible, because the strength and association of the unmeasured confounder with the exposure group and outcome must be very high to negate the observed effect [29].

\section{Power calculation}

A sample size of at least 150 with unequal groups achieves $99 \%$ power to reject the null hypothesis of equal means when the population difference in PPQ scores is 6 with a SD of 10 with a significance level (alpha) of 0.05 using a two sided two sample equal variance t-test (summary statement generated in PASS).

All statistical analyses were carried out using SAS, v. 9.4 (SAS Institute, Cary, NC, USA). E-values were then 
calculated using the R package "EValue" provided by the E-value creators [30].

\section{Results}

One hundred sixty-nine participants were recruited and 150 completed PPQ and PHQ-2 screening (Fig. 1). The majority of our sample was Hispanic (68\%), non-English speaking (67\%) and reported an annual income of $<\$ 20$, 000 (58\%). 34\% of the participants had a positive PHQ-2 screen and 33\% a positive PPQ screen (Table 1). Only 9 $(<7 \%)$ participants were fathers. Maternal education and language were not associated with PPQ or PHQ-2 scores. When looking at birth weight, gestational age, presence of neonatal comorbidities or use of equipment, there was no statistically significant differences between groups that screened positively and those who did not (Table 1).

As demonstrated in Fig. 2, after adjusting for confounders, we identified that a positive PHQ-2 depression score was associated with a negative unit $(95 \% \mathrm{CI})$ change on the infant's Vineland score of $-9.08(-15.6,-2.6)$ $(p<0.01)$ in 89 participants. There were no significant association between participant depression and stress scores and infant Bayley-III scores (motor or cognitive). As anticipated, use of medical equipment was associated (95\% CI) with lower Bayley-III motor and cognitive scores and VABS-II scores (Supplemental Tables 1 and 2) independent of PPQ screening: $-18.7(-27,-9.8)$ and $-24.3(-35$, -13) and-11.3 (-19, -4). Similarly, Bayley-III motor and cognitive scores $(95 \% \mathrm{CI})$ and VABS-II scores were lower independent of PHQ-2 screening, - 18.6 (-28, -
9.7) and $-24(-35,-13)$ and $-12(-19,-5)$. Additionally, while the sample was small, Black Non-Hispanic race was also associated (95\% CI) with lower Bayley-III motor scores, $-41(-66,-15)$ independent of PPQ screening, and independent of PHQ-2 screening, $-42(-67,-17)$ (Supplemental Table 1 and 2). After adjusting for observable confounders, there was no statistically significant association between PPQ or PHQ-2 screening and rehospitalizations and emergency room visits (Table 2).

Positive PPQ and PHQ-2 screening scores were associated with a negative unit $(95 \% \mathrm{CI})$ unit change on the participant Multicultural Quality of Life Index score of $-8.1(-12,-3.9)(p<0.01)$ and $-7.7(-12,-3)(p=$ 0.01 ) respectively (Fig. 3 and Supplemental Table 3). A subsequent E-value analysis demonstrated that the associated E-value (95\% CI) for PPQ was 2.27 (1.03) and for the PHQ-2 screen was 2.21 (1.62).

\section{Discussion}

More than one-third of the participants in this sample screened positively for PTSD and depression. Screening scores positive for stress and depression were associated with a negative change in some infant development scores and maternal quality of life scores. While studies have examined the impact of maternal mental health on the mother and fetus [31], few have examined the prevalence of PTSD and depression after NICU discharge in a diverse and underserved population as presented [32].

Studies have found that Hispanic and Black mothers have higher rates of post partum depression due to lack

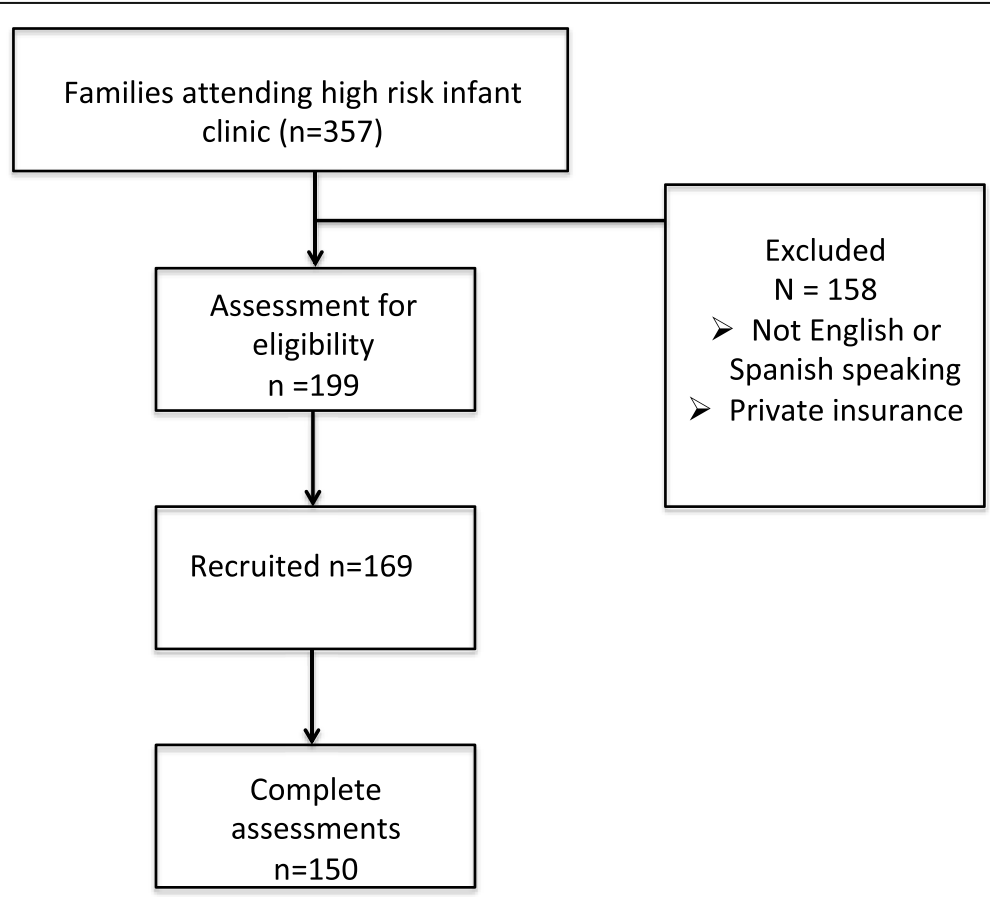

Fig. 1 Enrollment and recruitment 
Table 1 Socio-demographics and infant characteristics and caregiver mental health measure scores

\begin{tabular}{|c|c|c|c|c|c|c|c|c|}
\hline & \multicolumn{4}{|c|}{$\begin{array}{l}\text { Perinatal Post-traumatic Stress Disorder Questionnaire (PPQ) } \\
(N=139) \\
N(\%)\end{array}$} & \multicolumn{4}{|c|}{$\begin{array}{l}\text { Patient Health Questionnaire-2 (PHQ-2) }(N= \\
152) \\
N(\%)\end{array}$} \\
\hline & Total & Positive & Negative & $P$-value & Total & Positive & Negative & $P$-value \\
\hline Socio-demographics & & $46(33)$ & $93(67)$ & & & $51(34)$ & $99(66)$ & \\
\hline \multicolumn{9}{|l|}{ Person completing survey } \\
\hline Mother & 139 & $46(100)$ & $93(100)$ & $\mathrm{N} / \mathrm{A}$ & 141 & $50(98.0)$ & $91(91.9)$ & 0.17 \\
\hline Father & & & & & 9 & $1(2.0)$ & $8(8.1)$ & \\
\hline \multicolumn{9}{|l|}{ Race/ethnicity } \\
\hline White non-Hispanic & 10 & $1(2.3)$ & $8(8.7)$ & 0.32 & 10 & $2(3.9)$ & $8(8.3)$ & 0.07 \\
\hline Hispanic & 102 & $35(79.6)$ & $67(72.8)$ & & 109 & $41(80.4)$ & $68(70.1)$ & \\
\hline Black non-Hispanic & 14 & $6(13.6)$ & $8(8.7)$ & & 14 & $1(2.0)$ & $13(13.4)$ & \\
\hline Other & 11 & $2(4.6)$ & $9(9.8)$ & & 15 & $7(13.7)$ & $8(8.3)$ & \\
\hline \multicolumn{9}{|l|}{ Income (\$/Year) } \\
\hline Less than $\$ 20,000$ & 82 & $32(69.6)$ & $50(53.8)$ & 0.34 & 88 & $36(69.2)$ & $52(52.0)$ & 0.35 \\
\hline$\$ 20,001-\$ 40,000$ & 31 & $9(19.6)$ & $22(23.7)$ & & 35 & $9(17.3)$ & $26(26.0)$ & \\
\hline$\$ 40,001-\$ 60,000$ & 11 & $1(2.2)$ & $10(10.8)$ & & 14 & $4(7.7)$ & $10(10.0)$ & \\
\hline$\$ 60,001-\$ 80,000$ & 8 & $2(4.4)$ & $6(6.5)$ & & 7 & $2(3.9)$ & $5(5.0)$ & \\
\hline More than $\$ 80,000$ & 7 & $2(4.4)$ & $5(5.4)$ & & 8 & $1(1.9)$ & $7(7.0)$ & \\
\hline \multicolumn{9}{|c|}{ Highest level of education (either parent) } \\
\hline$\leq$ High school & 45 & $13(35.1)$ & $32(38.1)$ & 0.75 & 48 & $19(41.3)$ & $29(33.3)$ & 0.36 \\
\hline At least some college & 76 & $24(64.9)$ & $52(61.9)$ & & 85 & $27(58.7)$ & $58(66.7)$ & \\
\hline \multicolumn{9}{|l|}{ Language } \\
\hline Non-English & 93 & $33(71.7)$ & $60(64.5)$ & 0.39 & 101 & $39(76.5)$ & $62(62.6)$ & 0.09 \\
\hline English & 46 & $13(28.3)$ & $33(35.5)$ & & 49 & $12(23.5)$ & $37(37.4)$ & \\
\hline \multicolumn{9}{|l|}{ Infant characteristics } \\
\hline \multicolumn{9}{|l|}{ Birthweight (grams) } \\
\hline$<500$ to $<1000$ & 58 & $19(45.2)$ & $39(59.1)$ & 0.53 & 62 & $21(53.8)$ & $41(53.3)$ & 0.78 \\
\hline$\geq 1000$ to $<1500$ & 27 & $12(28.6)$ & $15(22.7)$ & & 31 & $11(28.2)$ & $20(26.0)$ & \\
\hline$\geq 1500$ to $<2500$ & 16 & $8(19.1)$ & $8(12.1)$ & & 16 & $6(15.4)$ & $10(13.0)$ & \\
\hline$\geq 2500$ & 7 & $3(7.1)$ & $4(6.1)$ & & 7 & $1(2.6)$ & $6(7.7)$ & \\
\hline \multicolumn{9}{|l|}{ Gestational age (weeks) } \\
\hline$<24$ to $<28$ & 52 & $16(34.8)$ & $36(51.4)$ & 0.19 & 56 & $20(48.9)$ & $36(43.4)$ & 0.66 \\
\hline$\geq 28$ to $<32$ & 45 & $21(45.7)$ & $24(34.3)$ & & 48 & $17(41.5)$ & $31(37.4)$ & \\
\hline$\geq 32$ to $<34$ & 12 & $7(15.2)$ & $5(7.1)$ & & 13 & $3(7.3)$ & $10(12.1)$ & \\
\hline$\geq 34$ to $<37$ & 7 & $2(4.4)$ & $5(7.1)$ & & 7 & $1(2.4)$ & $6(7.2)$ & \\
\hline \multicolumn{9}{|l|}{ Neonatal co-morbidities ${ }^{a}$} \\
\hline Yes & 94 & $36(78.3)$ & $58(62.4)$ & 0.06 & 102 & $35(67.3)$ & $67(67.0)$ & 0.97 \\
\hline No & 45 & $10(21.7)$ & $35(37.6)$ & & 50 & $17(32.7)$ & $33(33.0)$ & \\
\hline \multicolumn{9}{|c|}{ Use of medical equipment ${ }^{b}$} \\
\hline Yes & 43 & 15 (32.6) & $28(30.1)$ & 0.76 & 46 & $12(23.1)$ & $34(34.0)$ & 0.16 \\
\hline No & 96 & $31(67.4)$ & $65(69.9)$ & & 106 & $40(76.9)$ & $66(66.0)$ & \\
\hline \multicolumn{9}{|c|}{$\geq 2$ clinic appointments/month } \\
\hline Yes & 102 & $34(73.9)$ & $68(73.1)$ & 0.92 & 115 & $37(71.2)$ & $78(78.0)$ & 0.35 \\
\hline No & 37 & $12(26.1)$ & $25(26.9)$ & & 37 & $15(28.8)$ & $22(22.0)$ & \\
\hline
\end{tabular}

Post discharge diagnoses ${ }^{c}$ 
Table 1 Socio-demographics and infant characteristics and caregiver mental health measure scores (Continued)

\begin{tabular}{|c|c|c|c|c|c|c|c|c|}
\hline & \multicolumn{4}{|c|}{$\begin{array}{l}\text { Perinatal Post-traumatic Stress Disorder Questionnaire (PPQ) } \\
(N=139) \\
\mathrm{N}(\%)\end{array}$} & \multicolumn{4}{|c|}{$\begin{array}{l}\text { Patient Health Questionnaire-2 (PHQ-2) }(N= \\
152) \\
\text { N (\%) }\end{array}$} \\
\hline & Total & Positive & Negative & $P$-value & Total & Positive & Negative & $P$-value \\
\hline Yes & 100 & $37(80.4)$ & $63(90.0)$ & 0.14 & 107 & $37(90.2)$ & $70(84.3)$ & 0.42 \\
\hline No & 16 & $9(19.6)$ & $7(10.0)$ & & 17 & $4(9.8)$ & $13(15.7)$ & \\
\hline
\end{tabular}

Characteristics of neonates are shown as mean (standard deviation) for PPQ-14 and N (\%) for PHQ-2 scores. P-values derived using t-test (for 2 group comparison) and ANOVA test (for multi-group comparison) for continuous variables, and chi-square and fisher's exact test for categorical variables

${ }^{a}$ Neonatal co-morbidities include at least one diagnosis of: fetal growth restriction, surfactant deficiency, necrotizing enterocolitis, intraventricular hemorrhage grade 3 or 4, patent ductus arteriosus, retinopathy of prematurity

buse of medical equipment includes: oxygen, tracheostomy, wheelchair, adaptive stroller, feeding tube

'Post discharge diagnoses include at least one diagnosis of: attention deficit hyperactivity disorder, autism, global developmental delay, cerebral palsy

of social support, access, trust, past depression and other factors and Black women may even be less likely to seek treatment due to stigma [33]. Moreover, studies have found that among Hispanic women, acculturation was associated with higher rates of perinatal depression suggesting nativity may affect outcomes [34]. Previous maternal mental health disease has also been associated with lower levels of readiness for discharge [35]. In our sample, one third of participants screened positively for depression which is consistent with previous literature [36, 37]. Similarly, more than a third of participants screened positively for post-traumatic stress. Previous work has identified that maternal distress is often marked by post-traumatic stress, depression and anxiety and prevalent in mothers whose infants have been hospitalized in the NICU [38]. Understanding both the mother's personal history of mental health disorders, social complexity and support systems are important when interpreting depression and post-traumatic stress screening [39].
We identified a negative unit change in our VABS-II score among Spanish speaking families. Previous work has found that children of US-born Latinas with depression have poorer developmental outcomes than foreignborn Latinas [40]. Social capital has been found to improve maternal health of foreign-born Latina women [41]. Moreover, there is evidence of Latina paradox in some situations, where babies born to US-born Latina women face similar outcomes to Whites while babies of foreign-born Latinas have better outcomes in terms of prematurity and birthweight [42]. Similarly, it has been shown that among families with limited English proficiency, there were higher incidence rates of completion of influenza vaccines and preventive visits [43]. This has been attributed to concepts like "simpatia (politeness to avoid conflict)" or "respeto (respect)" as well as "marianismo" or female gender role in Hispanic culture. Moreover, it has been demonstrated that poverty, toxic stress and preterm birth can also impact developmental outcomes [44]. Also, while not appropriately powered, we identified that Black race was associated with worse

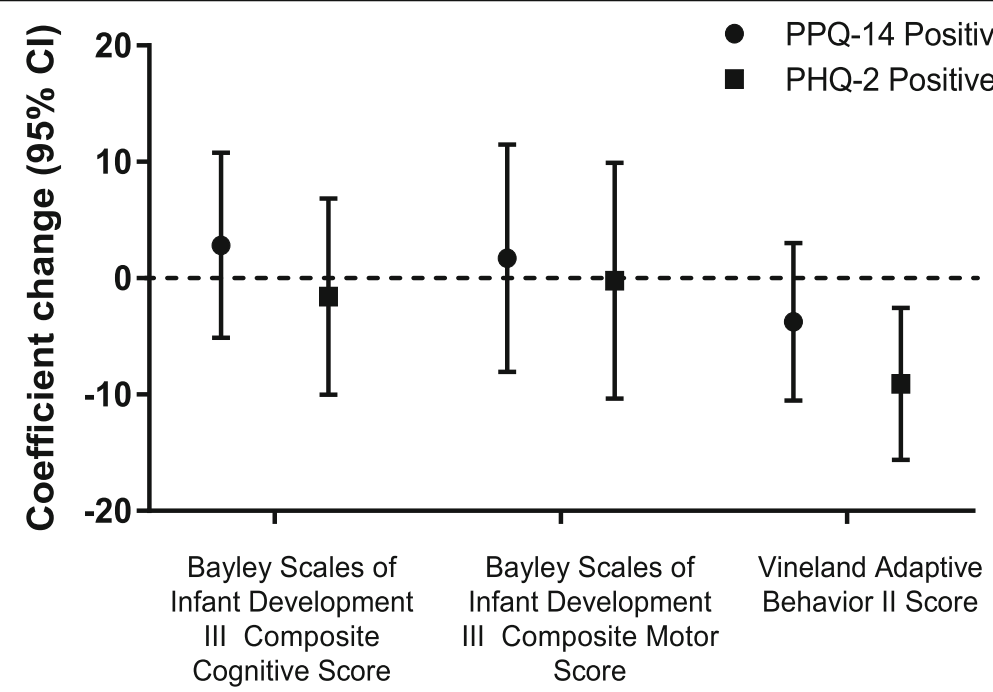

Fig. 2 Adjusted association of parents with positive post-traumatic stress and depression screening and child developmental outcomes ( $n=89$ ) 
Table 2 Adjusted association of maternal mental health measure scores and medical outcomes (re-hospitalization or emergency room visit)

\begin{tabular}{|c|c|c|c|c|c|}
\hline & $\begin{array}{l}\text { OR }(95 \% \\
\mathrm{Cl})\end{array}$ & $\begin{array}{l}P \text { - } \\
\text { value }\end{array}$ & & OR $(95 \% \mathrm{Cl})$ & $\begin{array}{l}P \text { - } \\
\text { value }\end{array}$ \\
\hline $\begin{array}{l}\text { Positive Perinatal Post-traumatic Stress Disorder Questionnaire } \\
\text { (PPQ) screen }\end{array}$ & $\begin{array}{l}1.29(0.5 \\
3.29)\end{array}$ & 0.6 & $\begin{array}{l}\text { Positive Patient Health Questionnaire- } \\
2 \text { Screen }\end{array}$ & $\begin{array}{l}1.06(0.42 \\
6.69)\end{array}$ & 0.89 \\
\hline \multicolumn{6}{|l|}{ Race } \\
\hline Non-Hispanic & Reference & & & Ref & \\
\hline Hispanic & $\begin{array}{l}1.17(0.34 \\
3.98)\end{array}$ & 0.8 & & $\begin{array}{l}1.16(0.34 \\
3.96)\end{array}$ & 0.82 \\
\hline \multicolumn{6}{|l|}{ Maternal Education } \\
\hline$\leq$ High School & Reference & & & Ref & \\
\hline Some college & $\begin{array}{l}1.46(0.53 \\
3.98)\end{array}$ & 0.46 & & $\begin{array}{l}1.44(0.52 \\
3.96)\end{array}$ & 0.48 \\
\hline \multicolumn{6}{|l|}{ Primary language } \\
\hline English & Reference & & & Ref & \\
\hline Non-English & $\begin{array}{l}0.64(0.21 \\
1.99)\end{array}$ & 0.44 & & $\begin{array}{l}0.61(0.2, \\
1.88)\end{array}$ & 0.39 \\
\hline \multicolumn{6}{|l|}{ Annual household income } \\
\hline Less than $\$ 20,000$ & $\begin{array}{l}1.6(0.54 \\
4.71)\end{array}$ & 0.52 & & $\begin{array}{l}1.57(0.52 \\
4.68)\end{array}$ & 0.56 \\
\hline$\$ 20,001-\$ 40,000$ & Reference & & & Ref & \\
\hline$\$ 40,001-\$ 60,000$ & $\begin{array}{l}1.67(0.23 \\
12)\end{array}$ & 0.66 & & $\begin{array}{l}1.72(0.24 \\
12.31)\end{array}$ & 0.64 \\
\hline More than $\$ 60,000$ & $\begin{array}{l}0.8(0.09 \\
6.96)\end{array}$ & 0.62 & & $\begin{array}{l}0.81(0.09 \\
7.04)\end{array}$ & 0.62 \\
\hline Infant chronologic age (month) & $\begin{array}{l}1.11(1.04, \\
1.9)\end{array}$ & 0.003 & & $\begin{array}{l}1.12(1.04 \\
1.20)\end{array}$ & 0.003 \\
\hline Medical equipment ${ }^{a}$ & $\begin{array}{l}3.47(1.24 \\
9.76)\end{array}$ & 0.02 & & $\begin{array}{l}3.48(1.24 \\
9.74)\end{array}$ & 0.02 \\
\hline
\end{tabular}

Adjusted odds ratios with $95 \%$ confidence intervals are shown vs. reference categories unless otherwise noted. Model adjusted for race/ethnicity, maternal education, language, annual household income, birth weight, use of medical equipment, and enrollment in early intervention

${ }^{a}$ Use of medical equipment includes: oxygen, tracheostomy, wheelchair, adaptive stroller, feeding tube

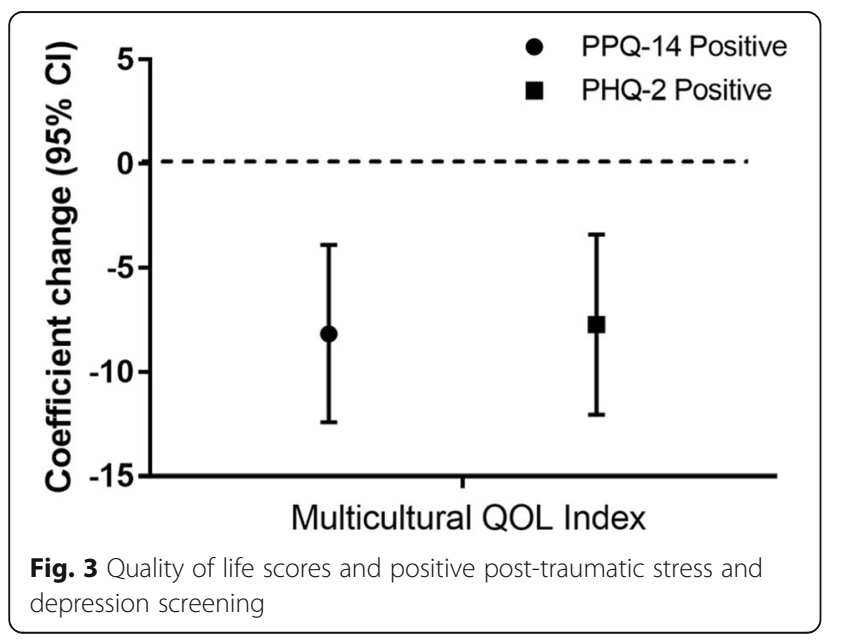

neurodevelopmental outcomes independent of parental stress or depression. A recent publication by the Eunice Kennedy Shriver National Institute of Child Health and Human Development Neonatal Research Network found that neurodevelopmental impairment has increased across all ethnic groups and not just minorities (increase from 2006 to 2014: black infants, 70\%; Hispanic infants, 123\%; white infants, 130\%) [45]. Studies have demonstrated that concepts like structural racism and discrimination are associated with maternal health outcomes [46-49] and future work should be conducted to demonstrate how they might impact our findings.

We did find a significant association between screening positive for post-traumatic stress and depression symptoms and lower quality of life scores. Previous studies have established how the act of caring for a preterm infant negatively affects family dynamics and maternal quality of life [5] but may improve over time [50]. In this study we used one of the same scales previously used to assess quality of life the Multicultural Quality of Life 
Index (MQLI) which assessed a mothers' overall health and well being including physical well being and social emotional support. Showing how maternal posttraumatic stress and depression symptoms affect quality of life establishes an important potential modifiable risk factor. We also conducted a sensitivity analysis with our E-value analysis and found that that a moderate confounder may affect our results. For example, for participants who screened positive for post-traumatic stress (PPQ), the associated E-value (95\% CI) was 2.27 (1.03) and for the PHQ-2 screen was 2.21 (1.62). Constructs like social support, living situation, nutrition and previous mental health disease and coping may also contribute to findings. Further evaluation is thus warranted on the possible protective effects increased social support and improved quality of life have on minimizing poor postpartum mental health and child health outcomes in preterm infants. This study reinforces the need to universally screen NICU mothers for PTSD and depression.

\section{Limitations}

This was a cross-sectional study; thus directionality of neither association nor causality is able to be determined. The tools used to assess post-traumatic stress and depression were screening tools and not diagnostic ones. Additionally, despite the strong association between Black race and worse outcomes on cognitive, motor and adaptive developmental screens seen in the adjusted logistic regression models, the sample size of Black mothers in the study was very small and was not powered to evaluate the association of race with developmental and adaptive behavioral outcomes. Moreover, given this study was done as a survey requiring literacy, those with literacy challenges who may represent a population with even greater socioeconomic barriers differing mental health outcomes, are not adequately captured in this study. Also, the power calculation was performed to detect the difference in PPQ scores and the secondary outcomes (infant and neurodevelopmental outcomes) were not powered.

\section{Future directions}

This study reinforces the need to universally screen NICU mothers for PTSD and depression. Additionally, dedicated evaluation on the association of race and cognitive and adaptive behavioral outcomes could help identifying other vulnerable populations who could potentially benefit from targeting resources and interventions. Specific parental treatment interventions have been shown to reduce trauma symptoms and depression [51, 52]. A recent meta-analysis has also demonstrated that cognitive behavioral therapy (CBT) is most effective to reduce depressive symptoms [53]. Telehealth and internet-based mental health services may also be promising solution for low-SES mothers and high-risk mothers (e.g., those in Neonatal Intensive Care Units) to access mental health services. Hynan et al. review steps to include telehealth services in providing psychosocial support to families, including using telemedicine for screening, maintaining compliance with the American Telemedicine Association and American Psychological Association, and for staff to familiarize themselves with web-based support sites [54, 55]. Several NICUs already employ web-based cameras, Skype, and FaceTime to allow parents to check on their hospitalized children. Augmenting these virtual connections might be a natural next step.

\section{Conclusions}

Screening scores positive for stress and depression symptoms were associated with a negative change in some infant development scores and maternal quality of life scores. Thoughtful screening programs for maternal stress and depression symptoms should be instituted.

\section{Supplementary Information}

The online version contains supplementary material available at https://doi. org/10.1186/s12884-020-03536-0.

Additional file 1: Supplemental Table 1. Association of maternal mental health measure scores and neurodevelopmental scores $(n=89)$. Supplemental Table 2. Association of maternal mental health measure scores and neurodevelopmental scores $(n=89)$. Supplemental Table 3. Association of maternal mental health measure scores and quality of life measures.

\section{Abbreviations \\ NICU: Neonatal Intensive Care Unit; PTS: Post traumatic stress; PTSD: Post traumatic stress disorder}

\section{Acknowledgments}

We would like to acknowledge: the support of the Teresa and Byron Pollitt Family Chair in Fetal \& Neonatal Medicine, Sylvia Magallon, RN for her assistance as the manager of the High Risk Infant Follow Up Program at the Fetal and Neonatal Institute for her assistance with recruitment, Ms. Griselda Monroy, Ms. Rachel Polcyn and Ms. Bernadette Lam for their assistance with data collection.

\section{Authors' contributions}

KG made contributions to analyzing the data and interpreting the results. KG wrote the first draft of the manuscript. AS contributed to data analysis. DLV, CYG, PSF and MK made contributions to designing the study. AL made substantial contributions to designing the study, analyzing the data, interpreting the results and revising the manuscript. All authors reviewed and approved of the final version of the manuscript.

\section{Funding}

This study was supported by the Confidence Foundation, the Saban Research Award and the Lucile Packard Young Investigator Award for Children with Special Health Care Needs. The funder provided support for patient incentives and research coordination support. 


\section{Ethics approval and consent to participate}

The Institutional Review Board at Children's Hospital Los Angeles approved the study protocol (CCl-13-00238). Written informed consent was obtained from all participants.

\section{Consent for publication}

Written consent was obtained from all participants.

\section{Competing interests}

The authors have no competing interests to disclose.

\section{Author details}

'Division of Neonatology, LAC+USC Medical Center, Keck School of Medicine, University of Southern California, Los Angeles, CA, USA. ${ }^{2}$ Fetal and Neonatal Medicine Institute, Division of Neonatal Medicine, Children's Hospital Los Angeles, Keck School of Medicine, University of Southern California, 4650 Sunset Boulevard, MS \#31, Los Angeles, CA 90027, USA. ${ }^{3}$ Department of Preventive Medicine, Johns Hopkins University, Baltimore, MD, USA. ${ }^{4}$ Section of Developmental-Behavioral Pediatrics, Children's Hospital Los Angeles, Keck School of Medicine, University of Southern California, Los Angeles, CA, USA. " Leonard D. Schaeffer Center for Health Policy and Economics, University of Southern California, Los Angeles, CA, USA. ${ }^{6}$ Division of Research on Children, Youth and Families, Children's Hospital, Keck School of Medicine, University of Southern California, Los Angeles, CA, USA. ${ }^{7}$ Department of Preventive Medicine, Keck School of Medicine, University of Southern California, Los Angeles, CA, USA.

Received: 8 September 2020 Accepted: 30 December 2020 Published online: 12 January 2021

\section{References}

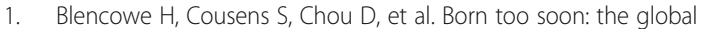
epidemiology of 15 million preterm births. Reprod Health. 2013;10(Suppl 1): S2.

2. Howson CP, Kinney MV, McDougall L, Lawn JE, Born Too Soon Preterm Birth Action G. Born too soon: preterm birth matters. Reprod Health. 2013; 10(Suppl 1):S1

3. Woythaler M, McCormick MC, Mao WY, Smith VC. Late preterm infants and neurodevelopmental outcomes at kindergarten. Pediatrics. 2015;136(3):42431.

4. Woythaler M. Neurodevelopmental outcomes of the late preterm infant Semin Fetal Neonatal Med. 2019;24(1):54-9.

5. Lakshmanan A, Agni M, Lieu T, et al. The impact of preterm birth $<37$ weeks on parents and families: a cross-sectional study in the 2 years after discharge from the neonatal intensive care unit. Health Qual Life Outcomes. 2017;15(1):38.

6. Pace CC, Anderson PJ, Lee KJ, Spittle AJ, Treyvaud K. Posttraumatic stress symptoms in mothers and fathers of very preterm infants over the first 2 years. J Dev Behav Pediatr. 2020;41(8):612-8.

7. Vanderbilt D, Bushley T, Young R, Frank DA. Acute posttraumatic stress symptoms among urban mothers with newborns in the neonatal intensive care unit: a preliminary study. J Dev Behav Pediatr. 2009;30(1):50-6.

8. Gavin NI, Gaynes BN, Lohr KN, Meltzer-Brody S, Gartlehner G, Swinson T. Perinatal depression: a systematic review of prevalence and incidence. Obstet Gynecol. 2005;106(5 Pt 1):1071-83.

9. DeMier RL, Hynan MT, Harris HB, Manniello RL. Perinatal stressors as predictors of symptoms of posttraumatic stress in mothers of infants at high risk. J Perinatol. 1996:16(4):276-80.

10. Holditch-Davis D, Bartlett TR, Blickman AL, Miles MS. Posttraumatic stress symptoms in mothers of premature infants. J Obstet Gynecol Neonatal Nurs. 2003;32(2):161-71.

11. Olshtain-Mann O, Auslander GK. Parents of preterm infants two months after discharge from the hospital: are they still at (parental) risk? Health Soc Work. 2008;33(4):299-308.

12. Padovani FH, Carvalho AE, Duarte G, Martinez FE, Linhares MB. Anxiety, dysphoria, and depression symptoms in mothers of preterm infants. Psychol Rep. 2009:104(2):667-79.

13. Northrup TF, Evans PW, Stotts AL. Depression among mothers of high-risk infants discharged from a neonatal intensive care unit. MCN Am J Matern Child Nurs. 2013;38(2):89-94.
14. Segre LS, Chuffo-Siewert R, Brock RL, O'Hara MW. Emotional distress in mothers of preterm hospitalized infants: a feasibility trial of nurse-delivered treatment. J Perinatol. 2013;33(12):924-8.

15. Gonulal D, Yalaz M, Altun-Koroglu O, Kultursay N. Both parents of neonatal intensive care unit patients are at risk of depression. Turk J Pediatr. 2014; 56(2):171-6.

16. Vigod SN, Villegas $L$, Dennis $C L$, Ross LE. Prevalence and risk factors for postpartum depression among women with preterm and low-birth-weight infants: a systematic review. BJOG. 2010;117(5):540-50.

17. Saigal S, Burrows E, Stoskopf BL, Rosenbaum PL, Streiner D. Impact of extreme prematurity on families of adolescent children. J Pediatr. 2000; 137(5):701-6.

18. McManus BM, Poehlmann J. Parent-child interaction, maternal depressive symptoms and preterm infant cognitive function. Infant Behav Dev. 2012; 35(3):489-98.

19. Flores-Fenlon N, Song AY, Yeh A, et al. Smartphones and text messaging are associated with higher parent quality of life scores and enrollment in early intervention after NICU discharge. Clin Pediatr. 2019;58(8):903-11. https://doi.org/10.1177/0009922819848080.

20. Lakshmanan A, Song AY, Flores-Fenlon N, et al. Association of WIC participation and growth and developmental outcomes in high-risk infants. Clin Pediatr. 2020;59(1):53-61.

21. Hynan MT, Mounts KO, Vanderbilt DL. Screening parents of high-risk infants for emotional distress: rationale and recommendations. J Perinatol. 2013; 33(10):748-53.

22. Callahan JL, Borja SE, Hynan MT. Modification of the perinatal PTSD questionnaire to enhance clinical utility. J Perinatol. 2006;26(9):533-9.

23. Lakkis NA, Mahmassani DM. Screening instruments for depression in primary care: a concise review for clinicians. Postgrad Med. 2015;127(1):99-106.

24. Kroenke K, Spitzer RL, Williams JB. The patient health questionnaire-2: validity of a two-item depression screener. Med Care. 2003;41(11):1284-92.

25. Anderson PJ, Burnett A. Assessing developmental delay in early childhood concerns with the Bayley-III scales. Clin Neuropsychol. 2017;31(2):371-81.

26. Sparrow SCD, Balla D. Vineland adaptive behavior scales. 2nd ed. Minneapolis: Pearson Assessment; 2005

27. Mezzich JE, Cohen NL, Ruiperez MA, Banzato CE, Zapata-Vega MI. The multicultural quality of life index: presentation and validation. J Eval Clin Pract. 2011:17(2):357-64.

28. Haneuse S, VanderWeele TJ, Arterburn D. Using the E-value to assess the potential effect of unmeasured confounding in observational studies. JAMA. 2019:321(6):602-3.

29. Gong CL, Song AY, Horak R, et al. Impact of confounding on cost, survival, and length-of-stay outcomes for neonates with hypoplastic left heart syndrome undergoing stage 1 palliation surgery. Pediatr Cardiol. 2020:41(5):996-1011.

30. Mathur MB, Ding P, Riddell CA, VanderWeele TJ. Web site and R package for computing E-values. Epidemiology. 2018:29(5):e45-7.

31. Heun-Johnson H, Seabury SA, Menchine M, Claudius I, Axeen S, Lakshmanan A. Association between maternal serious mental illness and adverse birth outcomes. J Perinatol. 2019:39(5):737-45.

32. Barroso NE, Hartley CM, Bagner DM, Pettit JW. The effect of preterm birth on infant negative affect and maternal postpartum depressive symptoms: a preliminary examination in an underrepresented minority sample. Infant Behav Dev. 2015:39:159-65.

33. Cannon C, Nasrallah HA. A focus on postpartum depression among African American women: a literature review. Ann Clin Psychiatry. 2019;31(2):138-43.

34. Lara-Cinisomo S, Wood J, Fujimoto EM. A systematic review of cultural orientation and perinatal depression in Latina women: are acculturation, Marianismo, and religiosity risks or protective factors? Arch Womens Ment Health. 2019;22(5):557-67.

35. McGowan EC, Du N, Hawes K, Tucker R, O'Donnell M, Vohr B. Maternal mental health and neonatal intensive care unit discharge readiness in mothers of preterm infants. J Pediatr. 2017;184:68-74.

36. Cherry AS, Blucker RT, Thornberry TS, Hetherington C, McCaffree MA, Gillaspy SR. Postpartum depression screening in the neonatal intensive care unit: program development, implementation, and lessons learned. J Multidiscip Healthc. 2016:9:59-67.

37. Slomian J, Honvo G, Emonts P, Reginster JY, Bruyere O. Consequences of maternal postpartum depression: a systematic review of maternal and infant outcomes. Womens Health (Lond). 2019;15:1745506519844044.

38. Staver MA, Moore TA, Hanna KM. Maternal distress in the neonatal intensive care unit: a concept analysis. Adv Neonatal Care. 2019;19(5):394-401. 
39. Wszolek K, Zurawska J, Luczak-Wawrzyniak J, Kopaszewska-Bachorz B, Glowinska A, Pieta B. Postpartum depression - a medical or a social problem? J Matern Fetal Neonatal Med. 2020;33(15):2556-60.

40. Harris RA, Santos HP Jr. Maternal depression in Latinas and child socioemotional development: a systematic review. PLoS One. 2020;15(3): e0230256.

41. Held ML, Cuellar M. Social capital and well-being: structural analyses of Latina mothers by nativity. Matern Child Health J. 2016;20(9):1948-55.

42. Flores ME, Simonsen SE, Manuck TA, Dyer JM, Turok DK. The "Latina epidemiologic paradox": contrasting patterns of adverse birth outcomes in $U$. S.-born and foreign-born Latinas. Womens Health Issues. 2012;22(5):e501-7.

43. Eneriz-Wiemer M, Saynina O, Sundaram V, Lee HC, Bhattacharya J, Sanders LM. Parent language: a predictor for neurodevelopmental follow-up care among infants with very low birth weight. Acad Pediatr. 2016;16(7):645-52.

44. Kelly MM, Li K. Poverty, toxic stress, and education in children born preterm. Nurs Res. 2019;68(4):275-84.

45. Travers CP, Carlo WA, McDonald SA, et al. Racial/ethnic disparities among extremely preterm infants in the United States from 2002 to 2016. JAMA Netw Open. 2020;3(6):e206757.

46. Alhusen JL, Bower KM, Epstein E, Sharps P. Racial discrimination and adverse birth outcomes: an integrative review. J Midwifery Womens Health. 2016; 61(6):707-20.

47. Thomas EV. "Why even bother; they are not going to do it?" The structural roots of racism and discrimination in lactation care. Qual Health Res. 2018; 28(7):1050-64

48. Bower KM, Geller RJ, Perrin NA, Alhusen J. Experiences of racism and preterm birth: findings from a pregnancy risk assessment monitoring system, 2004 through 2012. Womens Health Issues. 2018;28(6):495-501.

49. Chambers BD, Arabia SE, Arega HA, et al. Exposures to structural racism and racial discrimination among pregnant and early post-partum Black women living in Oakland, California. Stress Health. 2020;36(2):213-9.

50. McAndrew S, Acharya K, Westerdahl J, et al. A prospective study of parent health-related quality of life before and after discharge from the neonatal intensive care unit. J Pediatr. 2019;213:38-45.e33.

51. Shaw RJ, St John N, Lilo EA, et al. Prevention of traumatic stress in mothers with preterm infants: a randomized controlled trial. Pediatrics. 2013;132(4): e886-94.

52. Shaw RJ, St John N, Lilo E, et al. Prevention of traumatic stress in mothers of preterms: 6-month outcomes. Pediatrics. 2014;134(2):e481-8.

53. Mendelson T, Cluxton-Keller F, Vullo GC, Tandon SD, Noazin S. NICU-based interventions to reduce maternal depressive and anxiety symptoms: a metaanalysis. Pediatrics. 2017;139(3):e20161870.

54. Hynan MT, Steinberg Z, Baker L, et al. Recommendations for mental health professionals in the NICU. J Perinatol. 2015;35(Suppl 1):S14-8.

55. Hynan MT, Hall SL. Psychosocial program standards for NICU parents. J Perinatol. 2015;35(Suppl 1):S1-4.

\section{Publisher's Note}

Springer Nature remains neutral with regard to jurisdictional claims in published maps and institutional affiliations.

Ready to submit your research? Choose BMC and benefit from:

- fast, convenient online submission

- thorough peer review by experienced researchers in your field

- rapid publication on acceptance

- support for research data, including large and complex data types

- gold Open Access which fosters wider collaboration and increased citations

- maximum visibility for your research: over $100 \mathrm{M}$ website views per year

At $\mathrm{BMC}$, research is always in progress.

Learn more biomedcentral.com/submissions 